\title{
Clinical Translation in Tissue Engineering-The Surgeon's View
}

\author{
Constantin E. Dlaska ${ }^{1} \cdot$ Gunnar Andersson $^{2} \cdot$ Mats Brittberg $^{3} \cdot$ \\ Norbert P. Suedkamp ${ }^{4}$ - Michael J. Raschke ${ }^{5}$. Michael A. Schuetz ${ }^{1}$
}

Published online: 18 April 2015

(C) Springer International Publishing AG 2015

\begin{abstract}
Tissue engineering has raised the hopes of many surgeons to provide products, to restore the functionality of tissues and organs. The orthopedic surgeon could use these products to replace missing tissue due to trauma, infection, or surgical removal of necrotic or neoplastic tissue. Although research has shown large interest in TE, and number of publications in this field has increased tremendously in the last decade, there are still very few products available.

This review provides the view of leading surgeons and their view of TE in their area of expertise. Looking at spinal surgery, cartilage repair, tendon/ligament/muscle repair, large bone defects, and biomaterials, these experts report about the current demand, the current achievements, and the future of tissue engineering in the perspective of the surgeon. Furthermore, the difficulties of translating research results to usable products will be discussed.
\end{abstract}

This article is part of the Topical Collection on Molecular Biology of Skeletal Tissue Engineering

Constantin E. Dlaska

Constantin.Dlaska@gmx.at

1 Department of Orthopaedic and Trauma Surgery, Princess Alexandra Hospital and Queensland University of Technology, Brisbane, Australia

2 Department of Orthopaedic Surgery, Rush University Medical Center, Chicago, IL, USA

3 Region Halland Orthopaedics, Kungsbacka Hospital, University of Gothenburg, Gothenburg, Sweden

4 Department of Orthopaedic and Trauma Surgery, University Medical Center Freiburg, Freiburg, Germany

5 Department of Trauma, Hand and Reconstructive Surgery, Westfaelian-Wilhelms University Hospital Muenster, Muenster, Germany
Keywords Tissue engineering $\cdot$ Spine $\cdot$ Cartilage . Ligaments $\cdot$ Bone substitutes $\cdot$ Biomaterials

\section{Introduction}

Tissue engineering (TE) has raised the hopes and expectations in medicine in the last two decades since it was first mentioned in a publication in 1993. In a review published in the journal Science, R. Langer and J. P. Vacanti defined TE and described its potential [1]. Ever since then, almost every medical specialty is hoping to repair or replace tissue in the human body that is injured or damaged as a result of disease or trauma [2].

Charles A. Vacanti, one of the founders of TE, has once given a good definition: "Tissue engineering is a science devoted to the generation of new tissue by employing the principles of engineering in combination with the application of certain biologic principles." [2].

The current approach of TE is to generate new functional replacement tissue by seeding living cells onto appropriate configured scaffolds [2]. Further stimulation can be achieved by adding bioactive factors. Basic biologic research is necessary to supply and expand cells in vitro and to provide the bioactive factors. Engineering is required to create scaffolds with the necessary biological and structural properties.

From a clinical prospective, restoration of the bone, muscle, and soft-tissue defects are often related to tumors or more frequently to acute traumatic injuries. This can affect any civilian but are also often seen in military conflicts. Any highenergy trauma can cause direct tissue loss, or damage tissue to such an extent that it devitalizes or becomes prone to infection and requires secondary resection. From the US military statistics, we know that there were 51,000 combat casualties with 
severe limb injuries from the wars in Iraq and Afghanistan [3]. Forty-two percent of these diagnoses were from the musculoskeletal system and connective tissues [3]. Estimated lifetime cost (over 40 years) for the US military veterans with disabilities are between 69 and 120 billion dollars [3]. In 2008, the Department of Defense established the Armed Forces Institute of Regenerative Medicine (AFIRM) to help treat injured warfighters who have survived serious injuries [4]. The primary goals of AFIRM's Limb and Digit Salvage Program are to preserve and restore damaged or missing tissue following injury, reduce amputation rates, reduce the time and risks involved in recovery, and enable the warrior's return to an independent, fully functional life and, ideally, return to duty [4]. This institute received over 300 million dollars in their first 5 years of funding [4], which demonstrates the huge demand for tissue engineering products. Any advancement in this field will not only help soldiers, but trauma patients alike.

The interest in tissue engineering is also reflected in the number of publications, which have exponentially increased in the last decade. A PubMed search for "bone tissue engineering" reveals over 20,000 articles with a substantial increase of numbers of publication per year. Starting from only 340 publications in the year 2000, there are now over 2000 as of 2013 (Fig. 1). Although the interest in tissue engineering is high, very few discoveries have made it to a product outcome. Concerning this matter, it is necessary to mention that TE faces complex regulatory standards, resulting in high cost for laboratories, product safety, and manufacturing/ production.

In this review, we will discuss different areas with their challenges and elaborate on the impact of tissue engineering in these fields. We will explore the clinical demand, what we have achieved so far, and the future of TE in the perspective of the surgeon.

\section{Spinal Surgery}

Tissue engineering in the spine has primarily focused on the intervertebral disk, which degenerates over time in all humans

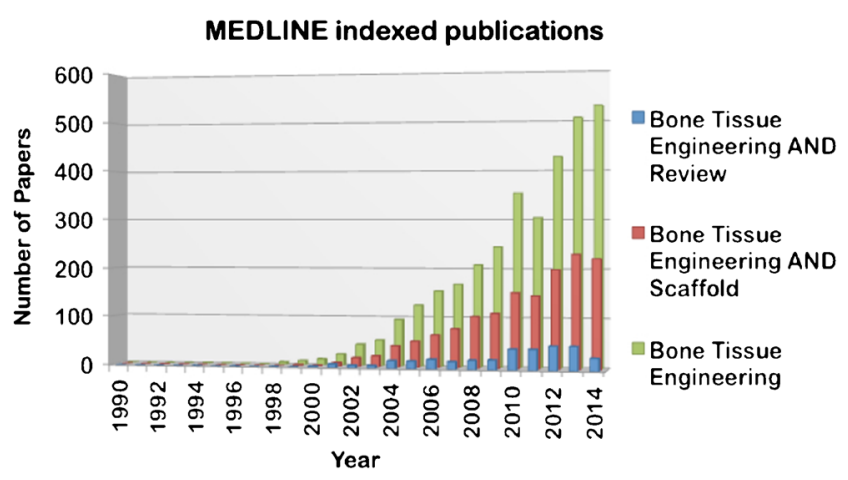

Fig. 1 Increase of number of publications in tissue engineering and can cause primary or secondary clinical problems. Three different approaches have primarily been used: injections of cells, engineering of nucleus pulposus replacement, and whole disk engineering.

A large number of studies involve injections of cells into animals from small to large. The animals injected include rats, rabbits, mini-pigs, dogs, pigs, sheep, and goats [5-10, 11•]. Typically, the degenerative process is initiated traumatically, and then the cells are injected (Fig. 2). In many studies, intervertebral disk-derived cells are used, but chondrocytes and mesenchymal stem cells are also commonly used. While in general results are promising, the question arises as to the relevance of these models to the clinical situation. Transplanted cells in humans may not be able to survive and produce appropriate tissue in the hostile environment of the human disk degeneration. The avascular environment may prevent the cells from functioning properly $[12,13 \cdot, 14-16]$.

Clinical trials using cell therapy are inconclusive, but promising. In the so-called Eurodisc study, intervertebral cells were transplanted 3 months following a single level diskectomy. Two years out results showed a reduction in pain and maintenance of disk height in the cell transplanted group compared to the diskectomy only group $[17,18]$. More recently, two preliminary US studies have also shown promising results [19•].

Engineered nucleus pulposus tissue has mostly used hydrogel scaffolds [20]. Because of the importance of nucleus pulposus to the normal function of the disk, this has been a logical area for study, particularly with a view of preventing degenerative changes following diskectomy of a herniated nucleus pulpous. Collagen-incorporated hydrogels [21, 22] and polymer-linked hydrogels [23] have also been used; none of these products have been successfully used in humans to date.

Whole disk engineering is complicated by the complex structures of the annulus fibrosus and nucleus pulposus and their different functions. Transplantations of whole intervertebral disks have been performed [24], but the practical application of this method is in question because of low availability of suitable tissue. Fixation and survival remain other obstacles. Other approaches to whole disk engineering include electrospun nanofibers enclosing hyaluronic acid [25]. Using sophisticated fabrication techniques, Nerurkar and colleagues [26] have engineered a functional annular and nuclear composite with mesenchymal stem cells. Other efforts involve composites of a cell-seeded synthetic polymer mesh wrapped around nucleus pulposus cell-seeded alginate [27] and a dual layer composite with bone matrix gelatin and chondrocyteseeded polymer [28]. None of these synthetic engineering efforts, however, have reached clinical application.

The most concerning aspect underpinning the tissue engineering process is the underlying etiology of disk degeneration. How long the engineered tissue will hold up and how 
Fig. 2 a Human distal diaphyseal tibial bone defect with inserted cement spacer. b Large bone defect model on an ovine tibia. The sheep model shows desired comparability to human tibia in regards to size and anatomy
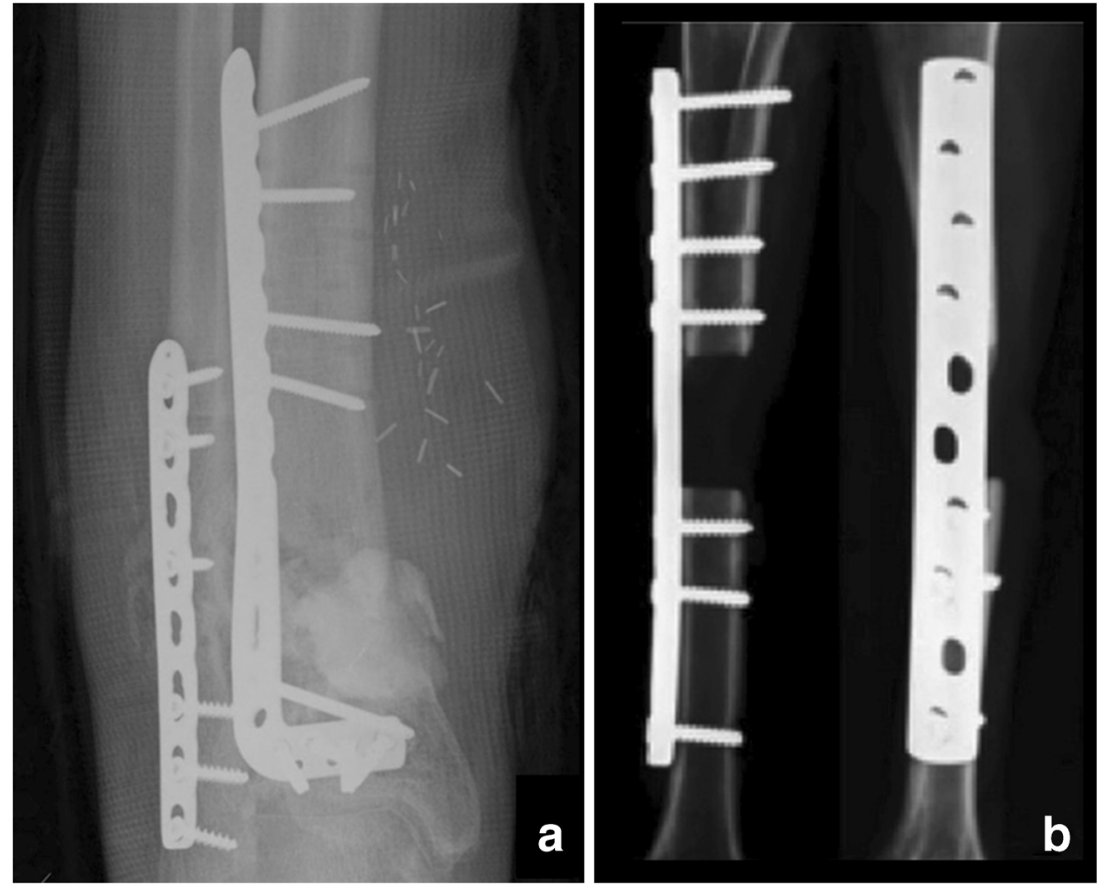

successful it will be in producing appropriate tissue in the hostile environment is still an open question. Also the diagnosis of the painful disk remains controversial. Still these efforts will continue with the potential of at least, in part, replacing our current invasive surgical methods.

\section{Cartilage Repair}

The cartilage is a troublesome tissue due to its poor ability to self-repair after injury. The cartilage is devoid of blood vessels, nerves, and lymphatic tissue. Hence, the repair is difficult to initiate [29].

Furthermore, when studying the possibilities to repair a damaged cartilage surface, one has to look at two types of damages:

1. Pure traumatic defects with more or less healthy surrounding cartilage.

2. Loss of cartilage due to pathology of the cells and matrix: osteoarthritis.

Sometimes, the damage is a mixture of traumatized cartilage and diseased cartilage due to other mechanisms. It could be seen as a gliding scale of tissue destruction where an isolated cartilage defect may remain like that without progress, while other injuries develop via a pre-osteoarthritic state into a full-blown osteoarthritis (OA). Concomitant injuries like meniscal loss and ACL injuries expedite OA development.
When a cartilaginous area has been damaged, an impairment of the joint function may develop. Symptoms like localized pain, locking phenomena, and decrease range of motion may occur. The patient seeks advice from the doctor, and $\mathrm{x}$ rays and MRI are performed [30]. A cartilaginous lesion may be noticed, and if regarded as being the cause of the pain situation, the surgeon suggests an arthroscopic evaluation and subsequent repair.

Small to large localized cartilaginous lesions, which are less than $50 \%$ of the surface depth, can be stabilized and treated with debridement. Lesions deeper than $50 \%$ of the surface depth, down to or through the subchondral bone plate may be treated by the following:

1. Bone marrow stimulation techniques

2. Cartilage tissue based repairs

3. Chondrogenic cell implantations

4. Synthetic or metal mini implants

Widespread loss of cartilage can be treated by unloading osteotomies or artificial arthroplasties.

The first three alternatives for local repairs can be augmented and combined with different matrices; these can be developed in vitro to either immature or mature grafts before implantation. The types of procedures developing a more or less mature cartilage graft for repair are called cartilage tissue engineering techniques.

The one and only cell in cartilage is the chondrocyte [29]. The chondrocyte is responsible for the matrix production [31], and such a cell seems the ideal cell to use for cartilage 
engineering [32]. However, these chondrogenic cells are not only found in joints but can also be found in the bone marrow, muscle, fat, and synovial tissue. Those so-called mesenchymal stem cells need to be driven into the chondrogenic pathway, to remain stable in a chondrogenic state and to produce a cartilaginous matrix of feasible clinical quality. As the mesenchymal stem cells are easier to harvest and used as allogeneic cells, the interest for widespread use of them has drastically increased. Today, there exist several mesenchymal stem cell-based technologies for tissue engineering of cartilage. The long-term durability and chondrogenic stability of tissues produced by those technologies remain to be shown. With the use of mature chondrocytes there exist several long-term studies showing good long-term clinical effects. Furthermore, in the last 11 years, 15 randomized studies have been performed with autologous chondrocytes implantation (ACI) [33, 34•, 35-47].

Eleven studies delineated ACI versus another technology, and seven studies outlined $\mathrm{ACI}$ against bone marrow stimulation (microfracture). In five out of seven of these studies, ACI was significantly better clinically than microfracture bone marrow stimulation in the different studied parameters [34•, $36,37,43,45]$.

What we have learned during the last 25 years is that all types of cartilage repair are slow, and a maturation process of the repair can be seen up to 3 years post-surgery. Knowing that it takes up to 20 years before the cartilage in a child reaches the morphology characteristics of mature adult cartilage, we have to understand that the long maturation time for the articular hyaline cartilage may take just as long.

ACI will remain of interest to use as an alternative to simpler techniques when they have failed. More studies on the use of one-stage repairs with mesenchymal stem cells of different origins will be seen. For all types of existing repair methods, the post-operative rehabilitation is the weakest part of the treatment. Not enough knowledge and empirical evidence exists for what rehabilitation protocol has the best outcomes. There is a tendency for faster rehab with early weight bearing. Recently, it was shown that significant quadriceps femoris strength deficits, gait deviations, and functional deficits persist for 5 to 7 years following ACI and microfracture surgical procedures [48]. When the tissue engineering approach is utilized, the above information is crucial when planning postoperative patient care.

In this previous section about cartilage, the focus has been on localized trauma defects and how they are treated. However, there is an enormous interest to intervene early on OA. Systemically administered MSCs have been shown to preferentially accumulate at sites of tissue damage and inflammation, thus MSC-based therapy holds great promise for the treatment of diseases such as OA and RA. However, we need to learn more about a normal development of a joint and how the different layers are made in order to one day regenerate a full repair tissue identical to the native tissue before damage.

\section{Tendon/Ligament Repair}

Tendon and ligament injuries still remain a challenge for surgeons to treat. It was assumed that tendon, ligament, and joint capsular injuries account for $45 \%$ of the 32 million musculoskeletal injuries each year in the US [49]. Current treatment strategies to repair tendon and ligaments, including tissue engineering approaches, are not able to reach the functional, structural, and biochemical properties of those of native tissue. In the following paragraphs, the major surgical problems for tendon, ligament, and muscle repair will be discussed, including the ruptured anterior cruciate ligament, the damaged Achilles tendon, and the torn rotator cuff.

The anterior cruciate ligament (ACL) possesses a limited healing capacity and consequently a need for reconstructive surgery. The tissue engineering approach includes transplantation of a cell-seeded scaffold. The suitable scaffold should mimic the biomechanical properties of the natural ACL; it needs to be biocompatible and biodegradable to enable tissue ingrowth, which is crucial for the new ligament to form. Collagen-based scaffolds have not obtained the stability and strength as seen from in vivo studies [50-52]. To overcome the mechanical weakness, silk-based scaffolds were developed [53], seeded with mesenchymal stem cells, and tested in large animal studies with encouraging results $[54,55]$. The outcome was supported by high biomechanical strength and cell proliferation. More recently, electrospinning has been used for the development of customized scaffolds for ligament tissue engineering and gives hope for "next generation" scaffolds [56•]. The majority of studies involving cell therapy approaches in ACL tissue engineering use mesenchymal stromal cells as a cell source, since they can be obtained in higher numbers and show higher proliferation and collagen productions rates as compared to ligament fibroblasts $[57,58]$.

Rotator cuff (RC) tears can be found in 30 to $50 \%$ of the population aged older than 50 years [59]. Surgical procedures to repair RC tears have shown great improvement over the years, but failure rates can range from 30 to $94 \%$ [60]. The idea of redirecting the healing process away from scar formation and toward the regeneration of a native tendon-bone insertion site is an attractive strategy of tissue engineering. The injection of muscle-derived stem cells into the supraspinatus tendon of rats resulted in a graft of transplanted cells with a morphology comparable to resident tendon fibers [61]. However, the ability of muscle-derived stem cells to improve tendon healing remains a goal of future studies.

For surgeons, the slow healing of the Achilles tendon is due to poor vascularity and represents another problem during 
therapy [62]. Non-operative treatment leads to scar tissue, which can lead to a loss of function. Operative treatment includes open or percutaneous sutures [63], which can be associated with infection, nerve damage, and adhesion formation [64]. Beside autograft and allograft augmentation, which have their own specified risks $[65,66]$, tissue engineering approaches are required. Two approaches are possible: the in vivo approach which allows regeneration of small lesions, while the ex vivo approach allows production of tissues which may be then used to repair larger lesions [67]. Calve et al. [68] produced an engineered rat Achilles tendon from tendonderived stem cells that was similar to an embryonic tendon in morphological and mechanical properties. Unfortunately, tendon-derived stem cells are in short supply at the donor site, are short-lived, and terminally differentiated [69]. These disadvantages prevent the use of parenchymal cells and recommend the application of mesenchymal stem cells (MSC) in the context of tissue engineering for tendons.

In two in vivo studies, MSC were injected into the torn tendon, which improved collagen fiber appearance, the quality and volume of tendon, as well as led to a $29 \%$ increased healing rate $[70,71]$. Another avenue to improve Achilles tendon repair is the use of growth factors (VEGF, SDF-1, IGF, CDMP), which are applied via direct repeated regional inoculation via gene vectors or via appropriate scaffolds [72-75].

Based on the above methodologies in tendon repair, the demands of surgeons with respect to tissue engineering have to be defined. In a recent questionnaire study by Rathbone et al. [76•], orthopedic surgeons were asked if they would use a tissueengineered ligament transplant. Eighty-six percent answered positively if the construct demonstrated biological and mechanical success. For surgeons, a tissue engineering approach requires a fully load-bearing construct for implantation, as well as the need for mechanical integrity. An important pre-condition for the stability of the transplants is the anisotropy of tissue-engineered tendon and ligament tissue, which might be provided by new nanostructured biomaterials.

Another important consideration is safety related to the use of growth factors, gene vectors, and stem cells. Further studies are needed to guarantee a reliable and secure application in clinical populations.

\section{Large Bone Defects}

Large bone defects are most commonly seen in the long bones of the extremities. The defect can be related to surgical excision of bone due to neoplasm, but is more often related to trauma and osteomyelitis. The treatment of these large bone defects can be very challenging, and current treatment options imply many disadvantages for the patient. Options include massive cancellousbone grafting [77], Papineau open cancellous-bone grafting [78], vascularized free fibula transfer [79, 80], the Masquelet induced membrane technique [81], and distraction osteogenesis with the Ilizarov method [82]. All of these methods demand bone graft or a bone graft substitute. Autografts are still the gold standard for any localized bone loss or as a source of stimulation for new bone formation [83]. Although it is effective, it comes with some drawbacks of minor to extensive donor site morbidities and limited bone graft quantity and quality. Distraction osteogenesis generates new bone but is a very lengthy treatment with multiple procedures, discomfort for the patient, and high risk of complications [84].

Each year, 3.2 million bone grafts are performed worldwide [83]. Currently available bone substitutes, including autografts, and synthetic materials, are the most implanted materials second only to transfused blood products worldwide [85]. Especially in trauma patients, the surgeon is confronted with large bone defect that requires greater amounts of bone substitute.

The great expectations within tissue engineering are to replace the autograft with a bone substitute that not only works as effective as the autograft, but also has more advantageous properties.

The current approach is to develop a scaffold with bone resembling structural stability, which is seeded with living cells. Additional growth factors, which are gradually released, are supposed to stimulate the host to incorporate [86] the scaffold and eventually replace it by bone regeneration $[87,88]$.

Recent advancement in 3D printing allows new configurations of scaffolds with placement of cells and growth factors in particular layers of the scaffold $[89,90]$. Another current approach is the use of hydrogels, which are synthetic polymer scaffolds. They can be loaded with bioactive substances and bone precursor cells. Additionally, they have a unique feature of in vivo self-formation, or self-assembly into matrices that are able to promote bone formation. This can be advantageous for minimally invasive surgeries [91-93].

So far, scaffolds have been tested only in animal studies and show limited success [94-99]. Beside the technical difficulties, clinical trial safety and efficacy are a huge challenge to implement these scaffolds in a product that can be used in humans (Fig. 3).

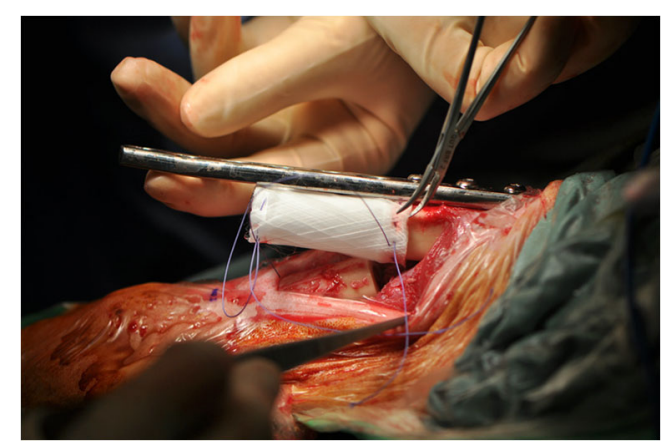

Fig. 3 Large bone defect sheep model treated with scaffold and bridging plate 
With tissue engineering, we hope one day to have the ideal bone substitute. This ideal bone substitute would be moldable, such that it could be used to fill a void [100]. During application, it would solidify so that it adds structural stability to the reconstructed bone [88]. Furthermore, the bone substitute should induce new bone formation in the host so that the substitute would be gradually replaced [101]. Current approaches include the seeding of the scaffold with living cells [102]. This limits the ability to store the bone substitute and also implies the risk of host rejection, transmission of diseases, or in case of autologous cells, it would demand time to expand the cell line. An ideal solution to this problem would be a scaffold that initiates the migration of stem cell of the host body into the scaffold.

The path to TE products for bone defects is still very long and expensive [101]. Companies working on these products will need large resources to overcome the challenges of basic research, animal testing, safety issues, and design/manufacturing. But the potential is enormous and will be helpful for the patient and the surgeon.

\section{Biomaterials}

The intention of using biomaterials in musculoskeletal trauma is to support traditional metal osteosynthesis in fracture treatment; biomaterials bear the potential to improve outcomes by contributing to the prevention of complications such as bone resorption, infections, or loss of reduction. With these objectives in mind, research currently focuses on combining established implant materials (i.e., titanium or steel) with surface modifications and coatings to actively influence the immediate surroundings of the implant, and with bone void fillers of various origin (mainly synthetic or allogeneic), to favor integration into the organism and subsequent replacement by autologous vital tissue [103-107].

Coating of metallic implants may improve results of internal fixation in clinically critical situations such as fractures in osteoporotic bone, non-unions, or infections. Incorporation and controlled release from coatings of bioactive substances such as growth factors, low molecular proteins, or other osteoanabolic substances in locally high concentrations could improve fracture healing in such critical situations [108•]. In the case of bacterial contamination and patients at higher risk of developing an implant-related infection, antimicrobial coatings lead to a high local concentration of antibiotics in critical areas such as the immediate surroundings of the implant, while avoiding systemic side effects.

However, the efforts to obtain regulatory approval for combination products are significant. Regulatory agencies, such as the FDA or other national authorities, require extensive preclinical and clinical evidence for the approval of such products, leading to prolonged approval cycles. Antibiotic coating on implants has recently been made available in the countries accepting a CE certification for approval. However, it is available on only one specific implant (an intramedullary tibial nail) and not on any other IM nails or implants. The approval of this same product in other regions of the world requires multiple clinical trials, e.g., in China, Japan, and the US. A prospective, randomized clinical trial, designed to prove a statistically significant reduction in post-operative infections, is estimated to cost in excess of 10 million USD, while still entailing significant risk due to the complex nature of fractures at risk of developing implant-related infections, patient heterogeneity, and the multifactorial origin of infections. Considering the various aspects involved in the development and approval of an antibiotic-coated implant for fracture treatment, development and approval are likely to require up to 10 or more years.

In the field of bone graft substitutes, surgeons are confronted with a wide variety of products to treat their patients. Only few can truly claim an osteoinductive effect, i.e., to stimulate bone growth: synthetic bone morphogenetic proteins, such as rhBMP2 and rhBMP7, and some allogeneic bone products, typically, demineralized bone matrix [109].

The combination of synthetic bone graft substitutes with autologous cells, in particular with bone marrow aspirate, is propagated and is a procedure that intuitively makes sense, adding potential osteogenic and osteoinductive properties to purely structural osteoconductive materials [110]. However, true clinical proof of efficacy is still pending. Nevertheless, this procedure may offer a good compromise between the safety and reproducibility of synthetic bone graft substitutes and the biological activity and safety of allogeneic tissue.

Finally, injectable synthetic bone graft substitutes, in the vast majority of cases with calcium phosphate-based materials, offer good handling properties and support fracture treatment with conventional metal implants $[111,112]$. In recent years, handling properties of these products have improved with some materials now explicitly being labeled for drilling through. Nevertheless, the ultimate product, which allows fracture fixation without the need for metal osteosynthesis, stimulates bone healing and finally remodels into healthy native bone, still only exists in the lab books of researchers and in the wish list of surgeons.

\section{Conclusions}

Tissue engineering is thought to be the solution for a lot of our problems in medicine. Although there has been great interest in this field, the surgeons are still missing products or techniques ready for use. Up to 2008, already approximately 4 billion dollars [113] have been invested in the pre-clinical phase of TE, but we are lacking the clinical translation of research results. 
In spinal surgery, there are efforts to replace damaged intervertebral disks with the help of TE. Whole intervertebral disks with an annulus and a nucleus have already been engineered from different materials. None of them have reached clinical application yet.

For localized traumatic cartilage lesions, we have some treatment options with autologous chondrocyte in vitro expansion and implantation. With further progress in TE, we hope to reduce the amount of procedures necessary and improve implant quality.

Current tendon and ligament repairs rely on scarring. With TE, the goal is to restore ruptures to fully functional tissue.

For large bone defects, there are multiple promising ideas with engineered scaffolds, which are seeded with stem cells and that release growth factors for stimulation of bone formation. This research is currently limited mainly to small animal models.

Successful clinical translation needs relevant pre-clinical models, which provides similar anatomy and comparable size translation, like in the clinical setting. Promising results from these studies will not only have easier applicability, but will also facilitate the conviction of surgeons to use it in the clinical human model.

We are facing many difficulties when it comes to the translation from research to products in tissue engineering. This transition has been previously described as the "valley of death" between research and clinical available products [113]: facing aspects of design/manufacturing, pre-clinical studies, and clinical trails of potential TE products. To overcome the "valley of death", we need good and relevant studies - mostly cost intensive large animal studies and clinical trails.

Funding for steps in the translational process can be challenging. Funding cannot only come from the governments and research programs, but the industry needs to be involved. Consequently, the necessity for TE and its current problems need to be well delineated.

Scientists researching in TE are often very focused on their problems of achieving certain results in their studies. Often in vitro or small animal models are used due to the easier availability, short maturity, and lower costs. However, these models have the disadvantage of low applicability to large animal models or humans, which are required for true translational research. Furthermore, from the surgeon's prospective, the products must be easy to handle and apply, be storable, but also must have a high success rate even in hostile recipient sites where soft tissues are compromised.

To address the challenges to meet the clinical need, translational research and design of a product as well as market introductions, a close and early partnership between clinicians, researchers, industry, and regulatory agencies, is and will be of utmost importance.

\section{Compliance with Ethics Guidelines}

Conflict of Interest Constantin E. Dlaska, Gunnar Andersson, Mats Brittberg, Norbert P. Suedkamp, Michael J. Raschke, and Michael A. Schuetz declare that they have no conflict of interest.

Human and Animal Rights and Informed Consent This article does not contain any studies with human or animal subjects performed by any of the authors.

\section{References}

Papers of particular interest, published recently, have been highlighted as:

- Of importance

1. Langer R, Vacanti JP. Tissue engineering. Science. 1993;260(5110):920-6.

2. Vacanti CA. History of tissue engineering and a glimpse into its future. Tissue Eng. 2006;12(5):1137-42.

3. Bilmes L. Soldiers returning from Iraq and Afghanistan: the longterm costs of providing veterans medical care and disability benefits. Faculty Research Working Papers Series-Harvard University -John F. Kennedy School of Government; 2007.

4. Pottol K. AFIRM annual report. 2013, AFIRM.

5. Sakai D et al. Transplantation of mesenchymal stem cells embedded in atelocollagen gel to the intervertebral disc: a potential therapeutic model for disc degeneration. Biomaterials. 2003;24(20): 3531-41.

6. Sakai D et al. Regenerative effects of transplanting mesenchymal stem cells embedded in atelocollagen to the degenerated intervertebral disc. Biomaterials. 2006;27(3):335-45.

7. Sakai D. Future perspectives of cell-based therapy for intervertebral disc disease. Eur Spine J. 2008;17 Suppl 4:452-8.

8. Henriksson HB et al. Transplantation of human mesenchymal stems cells into intervertebral discs in a xenogeneic porcine model. Spine (Phila Pa 1976). 2009;34(2):141-8.

9. Ganey $\mathrm{T}$ et al. Intervertebral disc repair using adipose tissuederived stem and regenerative cells: experiments in a canine model. Spine (Phila Pa 1976). 2009;34(21):2297-304.

10. Feng $\mathrm{G}$ et al. Transplantation of mesenchymal stem cells and nucleus pulposus cells in a degenerative disc model in rabbits: a comparison of 2 cell types as potential candidates for disc regeneration. J Neurosurg Spine. 2011;14(3):322-9.

11. Sakai D. and Andersson G. Stem cell therapy for intervertebral disc regeneration: obstacles and solutions. Nature Reviews Rheumatology 2015; (in press). This paper shows a good and recent overview of stem cell therapy for intervertebral disc regeneration.

12. Urban JP et al. Nutrition of the intervertebral disk. An in vivo study of solute transport. Clin Orthop Relat Res. 1977;129:10114.

13. Tibiletti M et al. Disc cell therapies: critical issues. Eur Spine J. 2014;23(3):S375-84. Demonstrates the difficulties to identify the patients which could profit of a cell therapy.

14. Risbud MV, Schipani E, Shapiro IM. Hypoxic regulation of nucleus pulposus cell survival: from niche to notch. Am J Pathol. 2010;176(4):1577-83.

15. Horner HA, Urban JP. Volvo award winner in basic science studies: effect of nutrient supply on the viability of cells from the 
nucleus pulposus of the intervertebral disc. Spine (Phila Pa 1976). 2001;26(23):2543-9.

16. Benneker LM et al. Cell therapy for intervertebral disc repair: advancing cell therapy from bench to clinics. Eur Cell Mater. 2014;27:5-11.

17. Meisel HJ et al. Clinical experience in cell-based therapeutics: disc chondrocyte transplantation. A treatment for degenerated or damaged intervertebral disc. Biomol Eng. 2007;24(1):5-21.

18. Meisel HJ et al. Clinical experience in cell-based therapeutics: intervention and outcome. Eur Spine J. 2006;15 Suppl 3:S397405 .

19. Coric D et al. Prospective study of disc repair with allogeneic chondrocytes presented at the 2012 Joint Spine Section Meeting. J Neurosurg Spine. 2013;18(1):85-95. Recent studies that have shown promising results.

20. Chiba $\mathrm{K}$ et al. Metabolism of the extracellular matrix formed by intervertebral disc cells cultured in alginate. Spine (Phila Pa 1976). 1997;22(24):2885-93

21. Alini $\mathrm{M}$ et al. The potential and limitations of a cell-seeded collagen/hyaluronan scaffold to engineer an intervertebral disclike matrix. Spine (Phila Pa 1976). 2003;28(5):446-54. discussion 453.

22. Collin EC et al. An injectable vehicle for nucleus pulposus cellbased therapy. Biomaterials. 2011;32(11):2862-70.

23. Endres $\mathrm{M}$ et al. Intervertebral disc regeneration after implantation of a cell-free bioresorbable implant in a rabbit disc degeneration model. Biomaterials. 2010;31(22):5836-41.

24. Ruan D et al. Intervertebral disc transplantation in the treatment of degenerative spine disease: a preliminary study. Lancet. 2007;369(9566):993-9.

25. Nesti LJ et al. Intervertebral disc tissue engineering using a novel hyaluronic acid-nanofibrous scaffold (HANFS) amalgam. Tissue Eng Part A. 2008;14(9):1527-37.

26. Nerurkar NL et al. Engineered disc-like angle-ply structures for intervertebral disc replacement. Spine (Phila Pa 1976). 2010;35(8):867-73.

27. Mizuno $\mathrm{H}$ et al. Biomechanical and biochemical characterization of composite tissue-engineered intervertebral discs. Biomaterials. 2006;27(3):362-70.

28. Wan Y et al. Biphasic scaffold for annulus fibrosus tissue regeneration. Biomaterials. 2008;29(6):643-52.

29. Mankin HJ. The structure, chemistry and metabolism of articular cartilage. Bull Rheum Dis. 1967;17(7):447-52.

30. Brittberg M, Winalski CS. Evaluation of cartilage injuries and repair. J Bone Joint Surg Am. 2003;85-A(2):58-69.

31. Muir $\mathrm{H}$. The intracellular matrix in the environment of connective tissue cells. Clin Sci. 1970;38(2):8p.

32. Brittberg $\mathrm{M}$ et al. Treatment of deep cartilage defects in the knee with autologous chondrocyte transplantation. N Engl J Med. 1994;331(14):889-95.

33. Bartlett $\mathrm{W}$ et al. Autologous chondrocyte implantation versus matrix-induced autologous chondrocyte implantation for osteochondral defects of the knee: a prospective, randomised study. J Bone Joint Surg (Br). 2005;87(5):640-5.

34. Basad E et al. Matrix-induced autologous chondrocyte implantation versus microfracture in the treatment of cartilage defects of the knee: a 2-year randomised study. Knee Surg Sports Traumatol Arthrosc. 2010;18(4):519-27. A recent study that showed a significant better 2 year outcome of autologous transplantation of chondrocyte compared to micro-fracturing.

35. Bentley $\mathrm{G}$ et al. A prospective, randomised comparison of autologous chondrocyte implantation versus mosaicplasty for osteochondral defects in the knee. J Bone Joint Surg (Br). 2003;85(2):223-30.
36. Cole BJ et al. Outcomes after a single-stage procedure for cellbased cartilage repair: a prospective clinical safety trial with 2-year follow-up. Am J Sports Med. 2011;39(6):1170-9.

37. Crawford DC, DeBerardino TM, 3rd Williams RJ. NeoCart, an autologous cartilage tissue implant, compared with microfracture for treatment of distal femoral cartilage lesions: an FDA phase-II prospective, randomized clinical trial after 2 years. J Bone Joint Surg Am. 2012;94(11):979-89.

38. Dozin B et al. Comparative evaluation of autologous chondrocyte implantation and mosaicplasty: a multicentered randomized clinical trial. Clin J Sport Med. 2005;15(4):220-6.

39. Gooding CR et al. A prospective, randomised study comparing two techniques of autologous chondrocyte implantation for osteochondral defects in the knee: periosteum covered versus type I/III collagen covered. Knee. 2006;13(3):203-10.

40. Horas $\mathrm{U}$ et al. Autologous chondrocyte implantation and osteochondral cylinder transplantation in cartilage repair of the knee joint. A prospective, comparative trial. J Bone Joint Surg Am. 2003;85-a((2)):185-92.

41. Knutsen $\mathrm{G}$ et al. A randomized trial comparing autologous chondrocyte implantation with microfracture. Findings at 5 years. J Bone Joint Surg Am. 2007;89(10):2105-12.

42. Lim $\mathrm{HC}$ et al. Current treatments of isolated articular cartilage lesions of the knee achieve similar outcomes. Clin Orthop Relat Res. 2012;470(8):2261-7.

43. Saris D et al. Matrix-applied characterized autologous cultured chondrocytes versus microfracture: 2-year follow-up of a prospective randomized trial. Am J Sports Med. 2014;42(6):1384-94.

44. Schneider U, Andereya S. First results of a prospective randomized clinical trial on traditional chondrocyte transplantation vs CaReS-Technology. Z Orthop Ihre Grenzgeb. 2003;141(5):496-7.

45. Vanlauwe J et al. Five-year outcome of characterized chondrocyte implantation versus microfracture for symptomatic cartilage defects of the knee: early treatment matters. Am J Sports Med. 2011;39(12):2566-74.

46. Visna $P$ et al. Treatment of deep cartilage defects of the knee using autologous chondrograft transplantation and by abrasive techniques - a randomized controlled study. Acta Chir Belg. 2004;104(6):709-14.

47. Zeifang $\mathrm{F}$ et al. Autologous chondrocyte implantation using the original periosteum-cover technique versus matrix-associated autologous chondrocyte implantation: a randomized clinical trial. Am J Sports Med. 2010;38(5):924-33.

48. Schmitt LC et al. Functional outcomes after surgical management of articular cartilage lesions in the knee: a systematic literature review to guide postoperative rehabilitation. J Orthop Sports Phys Ther. 2014;44(8):565-a10.

49. Butler DL, Juncosa N, Dressler MR. Functional efficacy of tendon repair processes. Annu Rev Biomed Eng. 2004;6:303-29.

50. Bellincampi LD et al. Viability of fibroblast-seeded ligament analogs after autogenous implantation. J Orthop Res. 1998;16(4): 414-20.

51. Dunn $\mathrm{MG}$ et al. Development of fibroblast-seeded ligament analogs for ACL reconstruction. J Biomed Mater Res. 1995;29(11): 1363-71.

52. Murray MM, Spector M. The migration of cells from the ruptured human anterior cruciate ligament into collagenglycosaminoglycan regeneration templates in vitro. Biomaterials. 2001;22(17):2393-402.

53. Panas-Perez E, Gatt CJ, Dunn MG. Development of a silk and collagen fiber scaffold for anterior cruciate ligament reconstruction. J Mater Sci Mater Med. 2013;24(1):257-65.

54. Altman GH et al. The use of long-term bioresorbable scaffolds for anterior cruciate ligament repair. J Am Acad Orthop Surg. 2008;16(4):177-87. 
55. Fan $\mathrm{H}$ et al. Anterior cruciate ligament regeneration using mesenchymal stem cells and silk scaffold in large animal model. Biomaterials. 2009;30(28):4967-77.

56. Cardwell RD, Dahlgren LA, Goldstein AS. Electrospun fibre diameter, not alignment, affects mesenchymal stem cell differentiation into the tendon/ligament lineage. J Tissue Eng Regen Med. 2014;8(12):937-45. This study showed that fiber diameter of a scaffold is more important than fiber alignment for the growth of in vitro tendons and ligaments.

57. Ge Z, Goh JC, Lee EH. Selection of cell source for ligament tissue engineering. Cell Transplant. 2005;14(8):573-83.

58. Huang TF et al. Isolation and characterization of mesenchymal stromal cells from human anterior cruciate ligament. Cytotherapy. 2008;10(8):806-14.

59. Riley $\mathrm{G}$. The pathogenesis of tendinopathy. A molecular perspective. Rheumatology (Oxford). 2004;43(2):131-42.

60. Rodeo SA et al. Biologic augmentation of rotator cuff tendonhealing with use of a mixture of osteoinductive growth factors. J Bone Joint Surg Am. 2007;89(11):2485-97.

61. Pelinkovic D et al. Muscle cell-mediated gene delivery to the rotator cuff. Tissue Eng. 2003;9(1):143-51.

62. Neufeld SK, Farber DC. Tendon transfers in the treatment of Achilles' tendon disorders. Foot Ankle Clin. 2014;19(1):73-86.

63. Maffulli $\mathrm{N}$ et al. Minimally invasive surgery of the Achilles tendon. Orthop Clin North Am. 2009;40(4):491-8. 4.

64. Maffulli N, Longo UG, Denaro V. Complications after surgery or nonoperative treatment for acute Achilles tendon rupture. Clin J Sport Med. 2009;19(5):441-2.

65. Salamon A et al. Submicroscopic investigation of autogenous tendon grafts. Acta Morphol Acad Sci Hung. 1970;18(1):23-42.

66. Yin $\mathrm{Z}$ et al. Stem cells for tendon tissue engineering and regeneration. Expert Opin Biol Ther. 2010;10(5):689-700.

67. Sharma P, Maffulli N. Tendinopathy and tendon injury: the future. Disabil Rehabil. 2008;30(20-22):1733-45.

68. Calve $\mathrm{S}$ et al. Engineering of functional tendon. Tissue Eng. 2004;10(5-6):755-61.

69. Ouyang HW et al. Mesenchymal stem cell sheets revitalize nonviable dense grafts: implications for repair of large-bone and tendon defects. Transplantation. 2006;82(2):170-4.

70. Ju YJ et al. Synovial mesenchymal stem cells accelerate early remodeling of tendon-bone healing. Cell Tissue Res. 2008;332(3):469-78.

71. Nourissat $\mathrm{G}$ et al. Mesenchymal stem cell therapy regenerates the native bone-tendon junction after surgical repair in a degenerative rat model. PLoS One. 2010;5(8):e12248.

72. Banes AJ et al. PDGF-BB, IGF-I and mechanical load stimulate DNA synthesis in avian tendon fibroblasts in vitro. J Biomech. 1995;28(12):1505-13.

73. Forslund C, Aspenberg P. CDMP-2 induces bone or tendon-like tissue depending on mechanical stimulation. J Orthop Res. 2002;20(6):1170-4.

74. Kurtz CA et al. Insulin-like growth factor I accelerates functional recovery from Achilles tendon injury in a rat model. Am J Sports Med. 1999;27(3):363-9.

75. Zhang $\mathrm{F}$ et al. Effect of vascular endothelial growth factor on rat Achilles tendon healing. Plast Reconstr Surg. 2003;112(6):16139 .

76. Rathbone S., N. Maffulli, and S.H. Cartmell. Most british surgeons would consider using a tissue-engineered anterior cruciate ligament: a questionnaire study. Stem Cells Int 2012;2012:303724. A recent study that showed that British orthopedic surgeons would consider using a tissue engineered ACL implant.

77. Christian EP, Bosse MJ, Robb G. Reconstruction of large diaphyseal defects, without free fibular transfer, in Grade-IIIB tibial fractures. J Bone Joint Surg Am. 1989;71(7):994-1004.
78. Papineau LJ et al. Chronic osteomyelitis: open excision and grafting after saucerization (author's transl). Int Orthop. 1979;3(3):165-76.

79. Han CS et al. Vascularized bone transfer. J Bone Joint Surg Am. 1992;74(10):1441-9.

80. Beris AE et al. Vascularized fibula transfer for lower limb reconstruction. Microsurgery. 2011;31(3):205-11.

81. Masquelet AC, Begue T. The concept of induced membrane for reconstruction of long bone defects. Orthop Clin North Am. 2010;41(1):27-37.

82. Ilizarov GA. Basic principles of transosseous compression and distraction osteosynthesis. Ortop Travmatol Protez. 1971;32(11): $7-15$.

83. Dinopoulos H, Dimitriou R, Giannoudis PV. Bone graft substitutes: what are the options? Surgeon. 2012;10(4):230-9.

84. Rozbruch SR. Drawbacks of bone transport with the Ilizarov method. J Orthop Trauma. 2003;17(4):318.

85. Horch RE. Future perspectives in tissue engineering. J Cell Mol Med. 2006;10(1):4-6.

86. Liu Y, Wu G, de Groot K. Biomimetic coatings for bone tissue engineering of critical-sized defects. J R Soc Interface. 2010;7(5): S631-47.

87. Rezwan $\mathrm{K}$ et al. Biodegradable and bioactive porous polymer/ inorganic composite scaffolds for bone tissue engineering. Biomaterials. 2006;27(18):3413-31.

88. Navarro $\mathrm{M}$ et al. Biomaterials in orthopaedics. J R Soc Interface. 2008;5(27):1137-58.

89. Lee JW et al. Bone regeneration using a microstereolithographyproduced customized poly(propylene fumarate)/diethyl fumarate photopolymer 3D scaffold incorporating BMP-2 loaded PLGA microspheres. Biomaterials. 2011;32(3):744-52.

90. Poldervaart MT et al. Sustained release of BMP-2 in bioprinted alginate for osteogenicity in mice and rats. PLoS One. 2013;8(8): e72610.

91. Behravesh E, Zygourakis K, Mikos AG. Adhesion and migration of marrow-derived osteoblasts on injectable in situ crosslinkable poly(propylene fumarate-co-ethylene glycol)-based hydrogels with a covalently linked RGDS peptide. J Biomed Mater Res A. 2003;65(2):260-70.

92. Behravesh $\mathrm{E}$ et al. Synthetic biodegradable polymers for orthopaedic applications. Clin Orthop Relat Res. 1999;367:S118-29.

93. Behravesh $\mathrm{E}$ et al. Synthesis of in situ cross-linkable macroporous biodegradable poly(propylene fumarate-co-ethylene glycol) hydrogels. Biomacromolecules. 2002;3(2):374-81.

94. Ai J et al. Tissue engineering using human mineralized bone xenograft and bone marrow mesenchymal stem cells allograft in healing of tibial fracture of experimental rabbit model. Iran Red Crescent Med J. 2012;14(2):96-103.

95. Viateau V et al. Long-bone critical-size defects treated with tissueengineered grafts: a study on sheep. J Orthop Res. 2007;25(6): $741-9$

96. Reichert JC et al. Bone tissue engineering. Reconstruction of critical sized segmental bone defects in the ovine tibia. Orthopade. 2012;41(4):280-7.

97. Reichert JC et al. A tissue engineering solution for segmental defect regeneration in load-bearing long bones. Sci Transl Med. 2012;4(141):141ra93.

98. Berner A et al. Autologous vs. allogenic mesenchymal progenitor cells for the reconstruction of critical sized segmental tibial bone defects in aged sheep. Acta Biomater. 2013;9(8):7874-84.

99. Reichert JC et al. Ovine bone- and marrow-derived progenitor cells and their potential for scaffold-based bone tissue engineering applications in vitro and in vivo. J Tissue Eng Regen Med. 2010;4(7):565-76.

100. Sethuraman $\mathrm{S}$ et al. Development and characterization of biodegradable nanocomposite injectables for orthopaedic applications 
based on polyphosphazenes. J Biomater Sci Polym Ed. 2011;22(4-6):733-52.

101. Schroeder JE, Mosh R. Tissue engineering approaches for bone repair: concepts and evidence. Injury. 2011;42(6):609-13.

102. Hutmacher DW. Scaffolds in tissue engineering bone and cartilage. Biomaterials. 2000;21(24):2529-43.

103. Liu $\mathrm{Y}$ et al. Incorporation of growth factors into medical devices via biomimetic coatings. Philos Trans A Math Phys Eng Sci. 2006;364(1838):233-48.

104. Lucke $\mathrm{M}$ et al. Gentamicin coating of metallic implants reduces implant-related osteomyelitis in rats. Bone. 2003;32(5):521-31.

105. Montali A. Antibacterial coating systems. Injury. 2006;37 Suppl 2: S81-6.

106. Raschke $\mathrm{M}$ et al. Insulin-like growth factor-1 and transforming growth factor-beta1 accelerates osteotomy healing using polylactide-coated implants as a delivery system: a biomechanical and histological study in mini-pigs. Bone. 2002;30(1):144-51.

107. Wildemann B et al. Local delivery of growth factors from coated titanium plates increases osteotomy healing in rats. Bone. 2004;34(5):862-8.
108. Fuchs T et al. The use of gentamicin-coated nails in the tibia: preliminary results of a prospective study. Arch Orthop Trauma Surg. 2011;131(10):1419-25. Preliminary results of a promising approach with antibiotic coated tibial nails to prevent infections.

109. Govender $\mathrm{S}$ et al. Recombinant human bone morphogenetic protein-2 for treatment of open tibial fractures: a prospective, controlled, randomized study of four hundred and fifty patients. J Bone Joint Surg Am. 2002;84-a(12):2123-34.

110. Orellana BR, Hilt JZ, Puleo DA. Drug release from calcium sulfate-based composites. J Biomed Mater Res B Appl Biomater. 2015;103(1):135-42.

111. Giannoudis PVet al. What should be the characteristics of the ideal bone graft substitute? Injury. 2011;42 Suppl 2:S1-2.

112. Larsson S, Bauer TW. Use of injectable calcium phosphate cement for fracture fixation: a review. Clin Orthop Relat Res. 2002;395: 23-32.

113. Hollister SJ. Scaffold engineering: a bridge to where? Biofabrication. 2009;1(1):012001. 